\title{
ENHANCEMENT OF EFFICIENCY OF NATURAL DYE ON HARVESTING SOLAR ENERGY BY INCORPORATED MONTMORILLONITE NANOPARTICLE
}

\author{
S. Mulijani", G. Syahbirin, A. Wulanawati, B. Marita, A. Saputra, Shabrina \\ and M. Nurbakti
}

Department of Chemistry, IPB University, Bogor-16680, (West Java) Indonesia

*E-mail: srimulijani@apps.ipb.ac.id

\begin{abstract}
Natural dye is widely considered by researchers for replacing the synthetic dye. The sensitizer in dye sensitizes solar cells on account of its containing double bond group in their molecule structure and the promising ability for donating and accepting an electron. In this research, we evaluate the performance of incorporated montmorillonite clay and polystyrene sulfonate to improve the efficiency of the dye-sensitized solar cell. Montmorillonite and polystyrene sulfonate were doped into $\mathrm{TiO}_{2}$ and then poured to the surface of ITO glass. Composite montmorillonitepolystyrene $/ \mathrm{TiO}_{2}$ was then immersed in anthocyanin as a natural dye that was extracted from red dragon fruit (Hylocereus polyrhizus). Performance functions of montmorillonite-polystyrene sulfonate, like a doped in dyesensitized solar cell, were evaluated by determination of photoconversion efficiency. Thermal gravimetric analysis was employed to evaluate the thermal stability of montmorillonite-polystyrene sulfonate. It was observed that the addition of montmorillonite-polystyrene sulfonate increased photoconversion efficiency.
\end{abstract}

Keywords: Montmorillonite, Natural Dye, Polystyrene Sulfonate, Photoconversion Efficiency, Dye Sensitizer.

(C) RASĀYAN. All rights reserved

\section{INTRODUCTION}

In recent times, harvesting solar energy has gained wide attention from researchers; as solar energy is (i) abundant on the earth, (ii) environment friendly and (iii) renewable. Several approaches have been evaluated to enhance the conversion efficiency of solar harvesting properties. Conversion technology of solar to electric power requires chemical dye which contains group function to convert photons from solar light to electric power. In this technology, the complex of ruthenium (II) based dye has been initiated to be employed for absorbing light throughout the visible spectrum and will achieve high efficiency in the existence of iodide as an electrolyte and achieved solar cell efficiency more than $10 \%$ under standard measurement ${ }^{1}$. Since the ruthenium is a hazardous element, toxic, carcinogenic and very costly, hence many researchers use natural dye to overcome these limitations and weakness of ruthenium. Galappaththi et $\mathrm{al}^{2}$, have developed design computational of cyanidin and benzothiadiazolylbenzoic acid (BTBA) based Density Functional Theory (DFT) and Time-Dependent Density Functional Theory (TDDFT) calculations. They considered that by modifying the sensitizer cyanidin sensitization ability to Dye-Sensitized Solar Cell (DSSC) will be promising. Other researchers also investigated the function of natural dye flavylium compound composited with $\mathrm{TiO} 2$ through DFT and TDDFT approach. It has been reported that pelargonidin dye is the best photosensitizer for DSSC based calculation of Highest Occupied Molecular Orbital (HOMO) and Lowest Occupied Molecular Orbital (LUMO). ${ }^{3,4}$

Therefore, natural dyes are considered promising as sensitizer and effectively replace synthetic dyes in conversion technology of solar energy to electric power. Other advantages are also reflected such as color and transparency properties, low cost of manufacture, ease of fabrication and modifiable aesthetic feature. The molecular structure of natural dye contains functional groups that can be acted as a donor or acceptor electron. The molecules included are flavonoids, betaines, carotenoids, tannin, cyanine, carotene and also chlorophylls ${ }^{5}$. However, the efficiency of conversion still needs to be improved; mainly the harvesting of

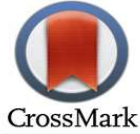


RASĀYAN J. Chem.

Vol. 13 | No. 3 |1612-1618| July - September | 2020

light remains very poor. Some researchers have utilized metal in conjunction with dye to increase the efficiency of the conversion of solar energy. Porphyrin as a natural dye in conjunction with cobalt-based redox mediators has revealed achievement in PCE of $13 \%{ }^{6}$. The use of inorganic metal is, however, not friendly with the environment.

In the above context, the introduction of inorganic particles compounded with polymer electrolyte has become an important alternative. The function of inorganic particles increases ionic conductivity and enhances the properties of materials such as mechanical and thermal stability ${ }^{7}$. It has been reported that the addition of clay such as montmorillonite (MMT) to polymer electrolyte will increase the melting temperature of the polymer electrolyte. Silicate layers in the MMT will act as nucleating agents for the crystallization of polymer. MMT contributes information of chemically distinct high melting complexes for interaction between silicate layers and the polymer chains ${ }^{8}$. However, investigation of MMT composite polystyrene sulfonate (PSS) for DSSC devices have not been reported yet. Kotta et al utilized a nitrogen source of melamine in doped $\mathrm{TiO} 2$ to increase cell efficiency from 26 with $10 \%$ of melamine to that of 86 with $90 \%$ melamine 9 .

The present study, therefore, targeted the development of DSSC devices by composite PSS and MMT. The performance of DSSC was investigated by determination of photoconversion efficiency, and thermal stability of composite MMT-PSS by Thermo Gravimetric Analyzer (TGA).

\section{EXPERIMENTAL}

\section{Materials}

The materials used in this research included ethanol $96 \%$, rutile phase $\mathrm{TiO}_{2}$ powder $(>35 \mathrm{~nm}$ ), Indium Tin Oxide (ITO) glass 15-25 $\Omega$ procured from Solaronix, styrofoam, oleum (Sigma Aldrich), $\mathrm{HCl} 32 \%$ pa, ethyl acetate pa, n-hexane pa, NaOH, chloroform, dichloromethane, Triton X-100 (Merck), red dragon fruit, methanol, glacial acetic acid, distilled water, Whatman 42 filter paper, carbon powder, potassium iodide, acetonitrile and $\mathrm{I}_{2}$.

\section{Synthesis of Polystyrene Sulfonated}

A total of $10 \mathrm{~g}$ of polystyrene (PS) was dissolved in $100 \mathrm{~mL}$ chloroform to obtain a polystyrene solution with a concentration of $10 \%(\mathrm{w} / \mathrm{v})$. Then in a three-flask neck, PS solution was heated to a constant temperature of $40^{\circ} \mathrm{C}$ while stirring using a magnetic stirrer. $20 \mathrm{~mL}$ of oleum dripped gradually in a separating funnel into a three-neck flask that was fed with nitrogen gas. $\mathrm{SO}_{3}$ gas would be pushed by nitrogen gas into PS solution. Polystyrene sulfonated synthesis was carried out for 60 minutes in an acid chamber. Thereafter polystyrene sulfonated was printed on a glass plate and dried for 8-10 hours.

\section{Preparation for Dye Extraction}

Dye extraction from red dragon fruit is carried out using maceration extraction. Red dragon fruit meat is separated from its skin and cut into small pieces, weighed $40 \mathrm{~g}$. Then extracted with citric acid and distilled water with a ratio of 1: 5. Stirring is carried out for 3 hours and filtered. Then, the maximum wavelength of dye was determined by UV-Vis Spectrophotometer Shimadzu UV-1601 with a wavelength range used $450-650 \mathrm{~nm}$.

\section{Preparation of Working Electrode}

The working electrodes were prepared by $3.5 \mathrm{~g}$ of $\mathrm{TiO}_{2}$ powder mixed with $15 \mathrm{~mL}$ of ethanol and then stirred to form a paste. The paste was added with 5 drops of Triton X-100 and stirred using a magnetic stirrer for 30 minutes. After that, $\mathrm{TiO}_{2}$ paste was deposited onto ITO substrate by a slip casting technique. The first step in this technique is that $2.5 \times 2.5 \mathrm{~cm}^{2}$ ITO glass is washed and rinsed using ethanol in a sonicator and then dried. The resistance is then measured using a digital multimeter on the conductive side (80-100 $\Omega$ ). Furthermore, in the first treatment $\mathrm{TiO}_{2}$ paste was deposited on the conductive side of ITO glass with an area of $1.5 \times 1.5 \mathrm{~cm}^{2}$ using a stirring rod then heated at a temperature of $155^{\circ} \mathrm{C}$ for \pm 30 minutes. Following this, ITO glass coated with $\mathrm{TiO}_{2}$ was immersed in a dye extract for 3 hours and dried using tissue paper. In the second treatment, $\mathrm{TiO}_{2}$ paste was added to $4 \mathrm{~mL}$ of dye and stirred until 
RASĀYAN J. Chem.

Vol. 13 | No. 3 |1612-1618| July - September | 2020

homogeneous. Also, $\mathrm{TiO}_{2}$ paste was deposited on the conductive side of ITO glass with an area of $1.5 \times$ $1.5 \mathrm{~cm}^{2}$ using a stirring rod then heated at $150^{\circ} \mathrm{C}$ for \pm 30 minutes.

\section{Preparation of Membrane Electrolyte}

Iodide / triiodide electrolyte solution is prepared by $0.8 \mathrm{~g}$ of potassium iodide dissolved in $10 \mathrm{~mL}$ of methanol and evenly mixed. Furthermore, $0.127 \mathrm{~g}$ of iodine are added to the solution until all three ingredients are completely dissolved. The solution is then stored in a dark-colored bottle. The polymeric material used to make electrolyte membranes were polystyrene sulfonated. A total of 4 drops of iodide/triiodide electrolyte solution was dropped into $2 \mathrm{~g}$ of PSS dissolved in $10 \mathrm{~mL}$ dichloromethane then stirred for 30 minutes

\section{Dye-Sensitized Solar Cell (DSSC) Assembly}

DSSC assembly was carried out using a sandwich coating technique, ITO glass coated with $\mathrm{TiO}_{2} / \mathrm{dye}$ smeared with an electrolyte membrane. Then taped with the comparative electrodes to the opposite, leaving two sides about $0.7 \mathrm{~cm}$. The left and right sides of the two electrodes were then clamped with clips so that they don't move. The solar cells were kept ready to be tested.

\section{DSSC Solar Cell Testing}

Voltage-current measurement (I-V) was measured by arranging solar cells in a test circuit, using a potentiometer or $100 \mathrm{k} \Omega$ resistors in series. DSC solar cell testing was performed using a solar light source whose intensity measured using a PMA 2200 photometer-radiometer. Current and voltage testing was carried out with a positive pole connected to the working electrode, while the negative pole on the comparison electrode was given variations ranging from small to large obstacles. This variation allowed us to determine the characteristics of solar cells to determine charging factors and their efficiency values.

\section{Thermal Characteristics of MMT-PSS}

\section{RESULTS AND DISCUSSION}

The PSS membrane melted at $548.73^{\circ} \mathrm{C}$ at a rate of $1.22 \mathrm{mg} / \mathrm{min}$. The weight loss was $29.99 \%$ of the initial membrane weight (Fig.-1a). As with the 3\% PSS-montmorillonite membrane, this membrane melts at a temperature of $553.51^{\circ} \mathrm{C}$ at a rate of $1.72 \mathrm{mg} / \mathrm{min}$. The weight loss was $35,878 \%$ of the initial weight (Fig.$1 \mathrm{~b})$. Changes in melting points on the two membranes indicate differences in membrane content. The addition of montmorillonite composites has increased the melting point of the membrane. Therefore, it can be stated that the addition of montmorillonite to polymer electrolyte strengthens thermal stability.

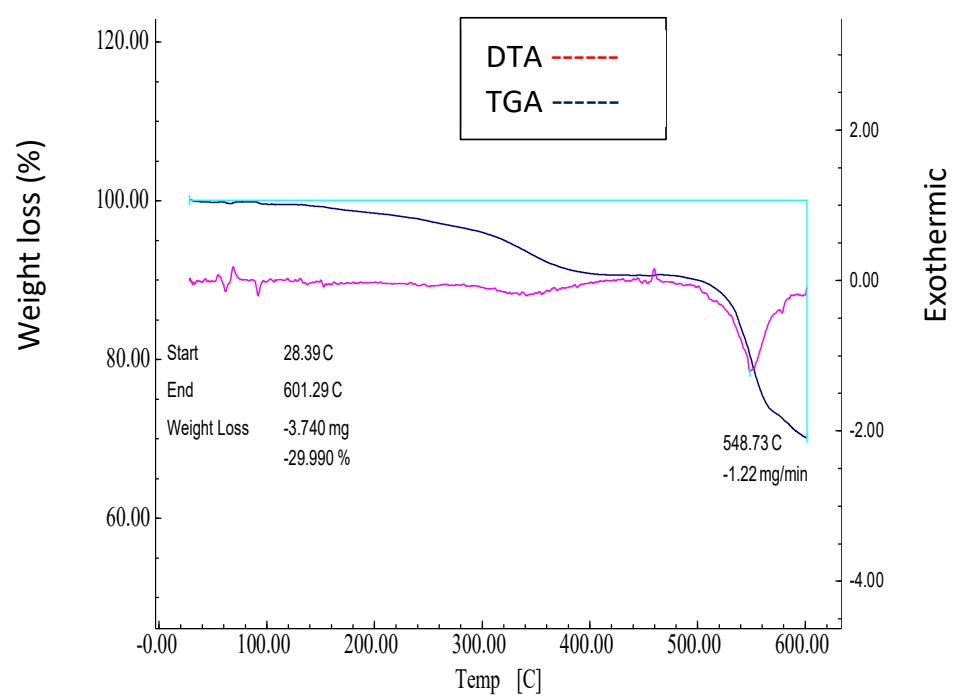

(a) 
RASĀYAN J. Chem.

Vol. 13 | No. 3 |1612-1618| July - September | 2020

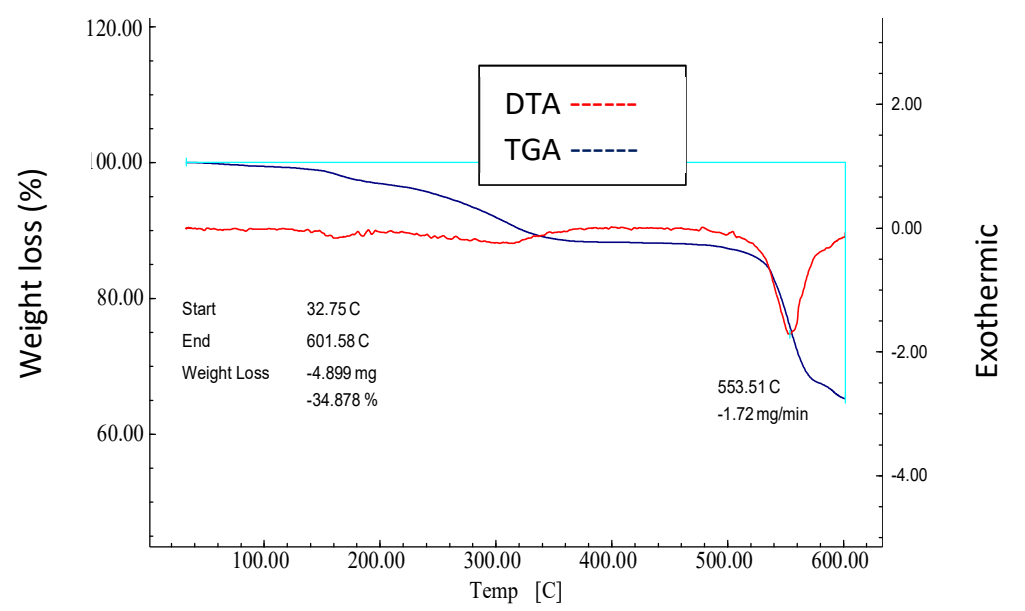

(b)

\section{Analysis of Function Group}

Fig.-1: (a) Thermogram of PSS and (b)PSS-Montmorillonite

Fourier Transform Infrared spectroscopy was employed to evaluate the functional group in PS and PSS. Figure-2 expressed the spectra of PS and PSS and exhibits the presence of the $-\mathrm{SO}_{3}$ functional group on the PSS membrane. The PS spectrum shows the peak of absorption at wavenumbers $1601-1452 \mathrm{~cm}^{-1}$ for $\mathrm{C}=\mathrm{C}$ aromatics, 1943-1772 $\mathrm{cm}^{-1}$ for benzene monosubstitutions, 2925-2850 $\mathrm{cm}^{-1}$ for $\mathrm{CH}\left(\mathrm{sp}^{2}\right)$, $3082-3026 \mathrm{~cm}^{-1}$ for $\mathrm{CHCHs}\left(\mathrm{sp}^{3}\right)$, and $757-701 \mathrm{~cm}^{-1}$ for monosubstituted $\mathrm{CH}$. The presence of sulfonate groups in PSS is evidenced by the new absorption peak at wave number $1200-1125 \mathrm{~cm}^{-1}$ for stretch vibration $-\mathrm{S}=\mathrm{O}$. The absorption area for the benzene compound is substituted for the position of the para- at the wave number $2000-1667 \mathrm{~cm}^{-1}$. The resulting PSS membrane spectrum reveals the absorption peak at wave number $1274 \mathrm{~cm}^{-1}$ for asymmetric strain $\mathrm{S}=\mathrm{O}$ and $1122.57 \mathrm{~cm}^{-1}$ for symmetric strain $\mathrm{O}=\mathrm{S}=\mathrm{O}^{10}$. This indicates the presence of sulfonate groups on the PSS membrane.

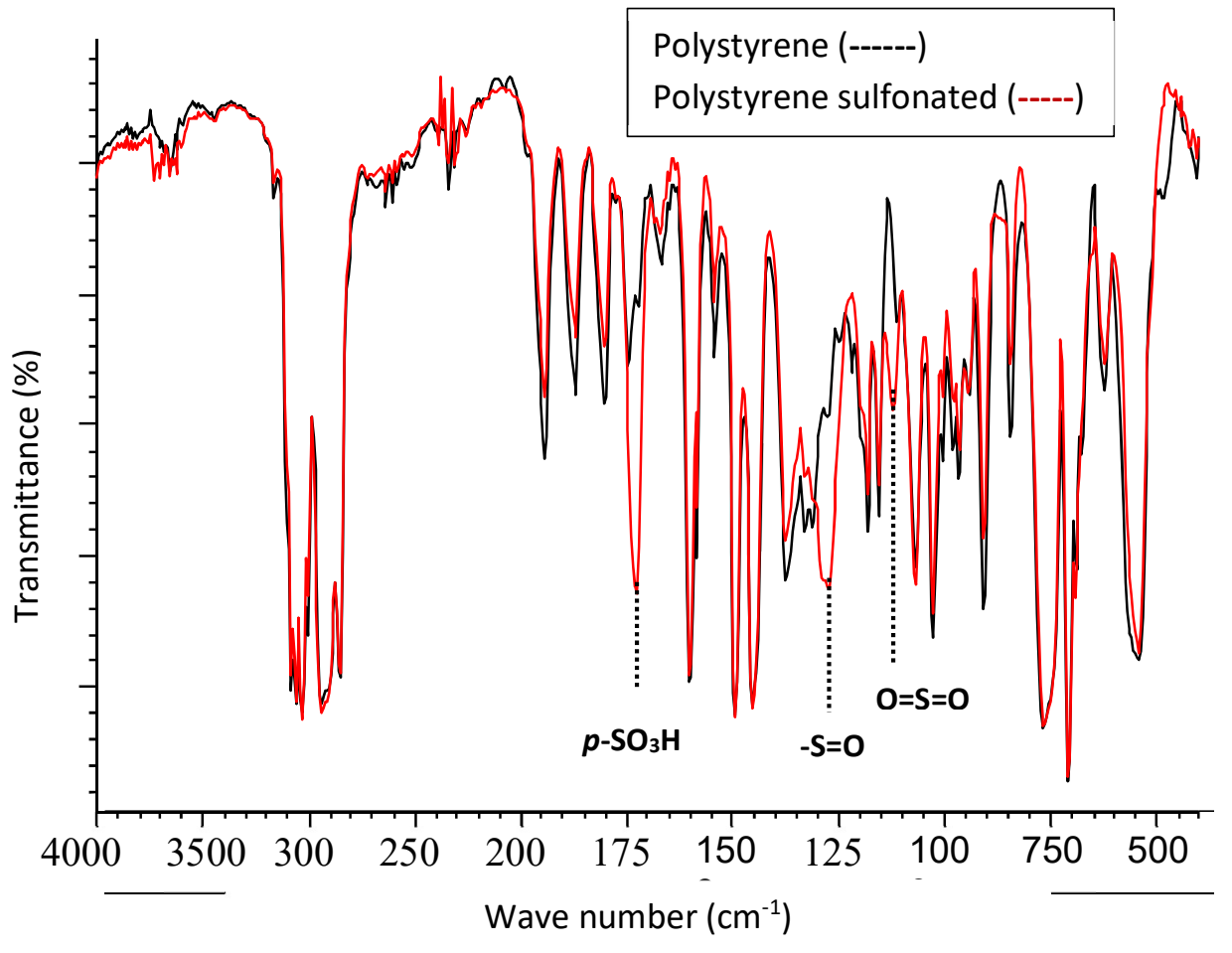

Fig.-2: Spectra of PSS ( $)$ and PS ( 
RASĀYAN J. Chem.

Vol. 13 | No. 3 |1612-1618| July - September | 2020

\section{Performance of DSSC}

Based on the results of UV-vis spectroscopy measurements, the peak absorption of the red dragon fruit extract exhibits at $\lambda=520$ and $516 \mathrm{~nm}$, it is predicted that the dye compound contained in the fruit is an anthocyanin type of pelargonidin 3-glucoside $(\mathrm{R}=\mathrm{H})(\text { Fig. }-3)^{11}$. The existence of double bonds conjugated in pelargonidin can be used as a sensitizer dye in DSSC that can absorb light in the range of visible light. Conjugated bonds in pelargonidin can undergo electronic transitions from $\pi$ to $\pi^{*}$. This causes the probability of electron injection into the semiconductor is quite high.<smiles></smiles>

Fig.-3: Structure of Pelargonidin-3-O-glucoside

Molecular orbitals and the electron transfer properties in pelargonidin are closely related to energy. This is very useful for identifying the best sensitizer for DSSC. The highest charged molecular orbital (HOMO) represents the ability to donate electrons; LUMO represents acceptor electron. For an efficient electron injection and regeneration process, the LUMO sensitizer must be above the edge of the $\mathrm{TiO}_{2}$ conduction band $(-4.0 \mathrm{eV})$ while the HOMO sensitizer must be below the energy level of the oxidation-reduction pair $(-4.8 \mathrm{eV})$.

Following the working principle of DSSC current flow, in the present study, DSSC performance of dye immersed and dye blended composite MMT/PSS was compared against PSS. Figure-4 shows photocurrent density-photovoltage measurements under IG6.8 $\mathrm{mW} / \mathrm{cm}^{2}$ and data of DSSC performance parameters have been concluded in Table-1.

Table-1: DSSC Performance Parameters

\begin{tabular}{c|c|c|c|c}
\hline \multirow{2}{*}{ Parameters } & \multicolumn{2}{|c|}{ PSS-TiO $/$ MMT } & \multicolumn{2}{c}{ PSS-TiO $_{2}$} \\
\cline { 2 - 5 } & Dye immersed & Dye blended & Dye immersed & Dye blended \\
\hline$V_{O C}(\mathrm{mV})$ & 38.2 & 18.7 & 20.4 & 18.7 \\
\hline$I_{S C}(\mathrm{~mA})$ & 0.037 & 0.023 & 0.022 & 0.01 \\
\hline$V m(\mathrm{mV})$ & 29.2 & 14.5 & 15.2 & 14.6 \\
\hline$I m(\mathrm{~mA})$ & 0.024 & 0.016 & 0.015 & 0.008 \\
\hline$F F(\%)$ & 49.58 & 53.94 & 50.80 & 0.4 \\
\hline$\eta(\%)$ & 4.5 & 1.5 & 1.4 & \\
\hline
\end{tabular}

The addition of PSS and MMT affects DSSC performance. PSS containing $\mathrm{SO}_{3} \mathrm{H}$ functional groups is inserted between dyes and $\mathrm{TiO}_{2}$. The function of PSS is to avoid the aggregation of dyes on the surface of $\mathrm{TiO}_{2}$ and recombination reaction between redox electrolytes and electrons in $\mathrm{TiO}_{2}$. Thus, the covalent bond formed between and $\mathrm{TiO}_{2}$ is stable. PSS also acts as a proton donor, which causes electrons to be fully injected from dyes into a conductive band in $\mathrm{TiO}_{2}$ and produce long-term chemical, thermal and electrochemical stability and pelargonidin will be oxidized efficiently.

In PSS- $\mathrm{TiO}_{2} /$ MMT the current value of the dyes immersed is higher than that of the dyes blended. In dyes blended PSS- $\mathrm{TiO}_{2} /$ MMT, dyes cover the surface of $\mathrm{TiO}_{2}$ and do not occur complex chelating with $\mathrm{TiO}_{2}$, thereby reducing electron injection into $\mathrm{TiO}_{2}$. The limitation of absorption of light by pelargonidin reduced the injection electron to a conductive band in $\mathrm{TiO}_{2}$ and causes a small value of efficiency. Another reason is electrons that are excited in molecular pelargonidin are unstable. Thus it predicted that the injection electron into the $\mathrm{TiO}_{2}$ conductive band or the electron returns to the ground state. The interaction between pelargonidin and $\mathrm{TiO}_{2}$ through chelate bonds causes electron injection into the $\mathrm{TiO}_{2}$ conduction band. 
RASĀYAN J. Chem.

Vol. 13 | No. 3 |1612-1618| July - September | 2020

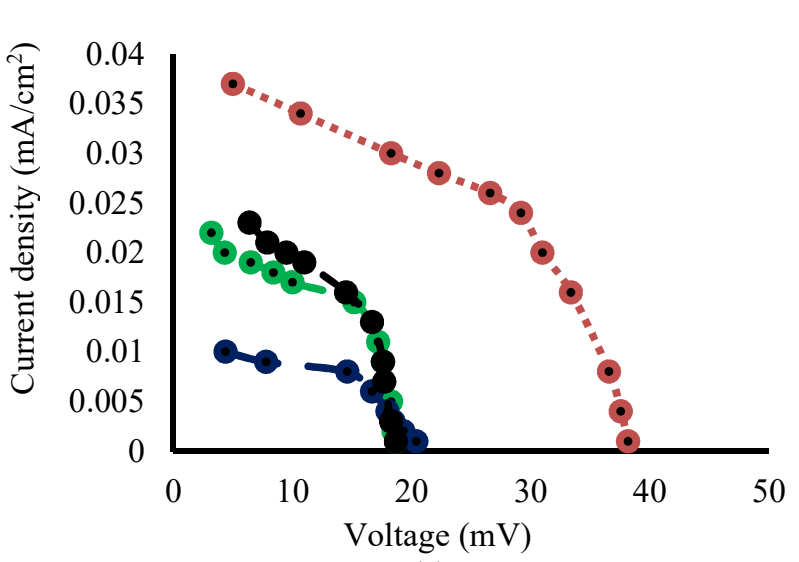

(a)

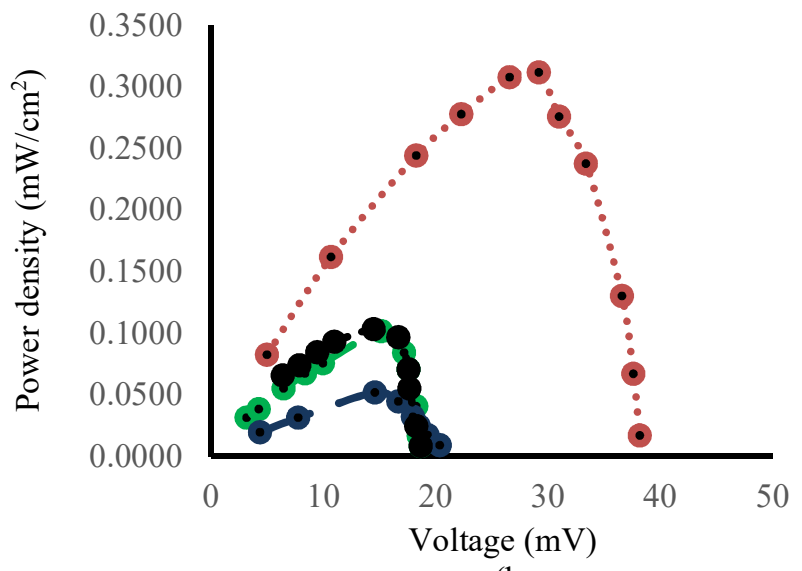

(b

Note :

Fig.-4: DSSC Performance Curves Obtained for the $\mathrm{TiO}_{2} / \mathrm{PSS}-\mathrm{MMT}-\mathrm{Dye}$

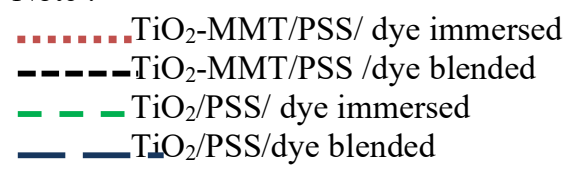

In the two devices, it can be seen the Voc of dye blended polymer electrolyte PSS into $\mathrm{TiO}_{2}$ and MMT into PSS- $\mathrm{TiO}_{2}$ are similar. This can be attributed to the composition of DSSC that contains the same electrolyte, electrode and carbon electrode ${ }^{12}$. Dye blended in the PSS-TiO 2 and PSS- $\mathrm{TiO}_{2}-\mathrm{MMT}$ exhibits very weak courage to increase the efficiency of DSSC, because dye occupied the hole of surface $\mathrm{TiO}_{2}$ and influenced the surface, thereby limiting the capture of the electron. However, MMT-dye immersed has contributed to increasing the photoconversion efficiency. The dye immersing process employed MMT ability to do adsorption organic dye. The dye has high light absorbance ability in its absorption wavelength range ${ }^{13}$. MMT nanoparticle film on ITO/PSS substrate, which was immersed in the dye solution, revealed the highest efficiency compared with the blended process and without MMT (Fig.-5).

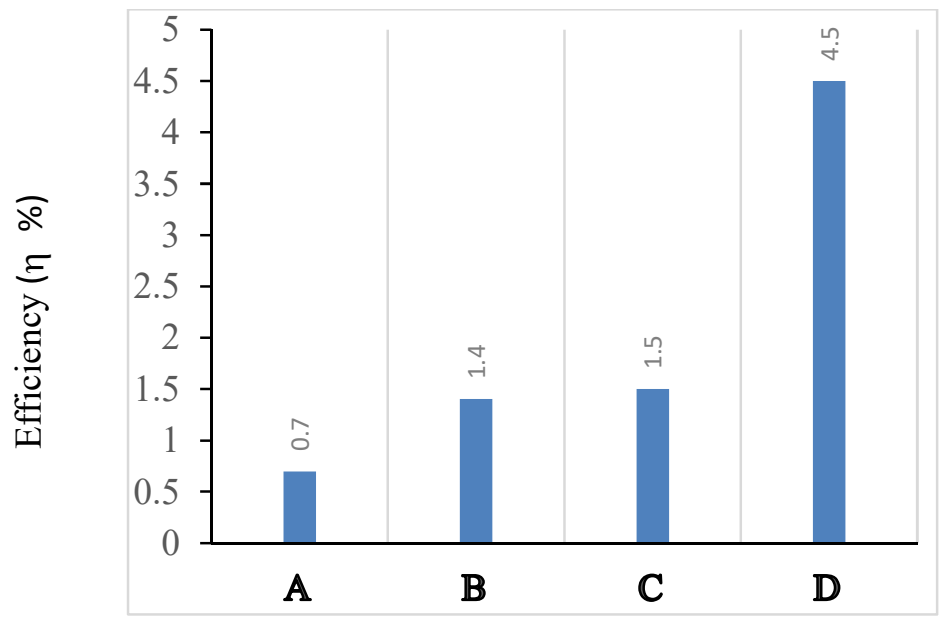

Fig.-5: Effect of MMT towards efficiency

$\mathrm{A}=\mathrm{TiO}_{2}$-PSS- dye blended, $\mathrm{B}=\mathrm{TiO}_{2}$-PSS- dye immersed, $\mathrm{C}=\mathrm{TiO}_{2}$-PSS-MMT-dye blended, $\mathrm{D}=\mathrm{TiO}_{2}$-PSS-MMTdye immersed

The Addition of PSS and MMT in DSSC increases the ionic conductivity $(\sigma=59.92 \mathrm{mS} / \mathrm{cm})$ and photoconversion efficiency $(\eta)$. These results suggest that lone pairs electron in the PSS would be 
RASĀYAN J. Chem.

Vol. 13 | No. 3 |1612-1618| July - September | 2020

transferred by Iodine on $\mathrm{I} / \mathrm{I}_{3}$-redox couple and it causes short circuit current density and open-circuit voltage in the solar cell increasing PSS is a polymer electrolyte and composited with polymer MMT which contents layers structure of clay produces structure change immensely within PSS has more number of sulfonate group which can easily capture the electron in the cell. Polymer electrolyte PSS and MMT immersed with dye organic is a promising candidate for dye-sensitized solar cell.

\section{CONCLUSION}

Composite MMT-PSS were fabricated using dye direct immersed and blending process of natural dye. The study established that the addition of MMT-PSS into $\mathrm{TiO} 2$ results in enhanced photoconversion efficiency $(\eta)$ and also conductivity of ion in DSSC, both in dye direct immersed and blending process. However, photoconversion efficiency ( $\eta$ )DSSC of dye was higher in the case of a direct immersed process as compared to the dye direct blending process. The thermal stability of material composite MMT-PSS was more stable compared to its PSS. Therefore, MMT-PSS could enhance the stability of natural dye in DSSC assemble and it has promising consideration as a material for DSSC.

\section{ACKNOWLEDGEMENT}

We express our gratitude to the Ministry of Research and Technology Indonesia for providing funding for this research.

\section{REFERENCES}

1. Y. Qin, Q. Peng, International Journal of Photoenergy, Article ID 291579(2012), DOI: $10.1155 / 2012 / 291579$

2. K. Galappaththi, A. Lim, P. Ekanayake, and M. I. Petra, International Journal of Photoenergy, Article ID 8564293 (2017), DOI: $10.1155 / 2017 / 8564293$

3. M. Lakshmanakumar, S. Sriram and D. Balamurugan, Journal of Computational Electronics, 17, 1143(2018)

4. L. Muthaiyan1, S. Sriram, B. G. Jeyaprakash, and D. Balamurugan, Rasayan Journal of Chemistry, 10(4),1417(2017), DOI:10.7324/RJC.2017.1041913

5. H. Zhou, L. Wu, Y. Gao, T. Ma, Journal of Photochemistry and Photobiology A : Chemistry, 219,188(2011), DOI:10.1016/j.jphotochem.2011.02.008

6. S. Mathew, B. F.E.Curchod, , A. Yella, P. Gao, R. Humphry-Baker, N. A. Astani, I. Tavernelli, U. Rothlisberger, Md. K. Nazeeruddin and M. Gra"tzel, Nature Chemistry, 6, 242(2014), DOI: 10.1038/nchem. 1861

7. H. Darmokoesoemo, H. Setyawati, A.T.A. Ningtyas and H.S. Kusuma, Rasayan Journal of Chemistry, 10, 313(2017), DOI:10.7324/RJC.2017.1021561

8. C. H. Lee, K. Liu, S. H. Chang, K. J. Lin, J. J. Lin, K. C. Ho, K. F. Lin, Journal of Colloid and Interface Science, 363(2),635(2011), DOI:10.1016/j.jcis.2011.08.009

9. A. Kotta, S. A. Ansari, N. Parveen, H. Fouad, O.Y. Alothman, U. Khaled, H. K. Seo, S. G. Ansari, Z. A. Ansari, Journal of Materials Science: Materials in Electronics, 29, 9108(2018), DOI: $10.1007 / \mathrm{s} 10854-018-8938-y$

10. S. Mulijani, K.Dahlan and A. Wulanawati, International Journal of Materials, Mechanics and Manufacturing, 2(1), 36(2014), DOI:10.7763/IJMMM.2014.V2.95

11. L. Mander and H.B.Liu, Comprehensive Natural Products II: Chemistry and Biology, Elsevier Ltd, Kidlington OX5 1GB, United Kingdom, p. 570(2010).

12. X. Chen, Y. Tang and W. Liu, Molecules, 22(8),1284(2017), DOI:10.3390/molecules22081284

13. L. Zhang, A. Konno, International Journal of Electrochemical Science, 13, 344(2018), DOI: 10.0964/2018.01.07

[RJC-5649/2020] 